\title{
Intravenous AAV8 Encoding Urocortin-2 Increases Function of the Failing Heart in Mice
}

\author{
N. Chin Lai, ${ }^{1,2}$ Mei Hua Gao,,2 Dimosthenis Giamouridis, ${ }^{1,2, *}$ Jorge Suarez,, ${ }^{2, *}$ Atsushi Miyanohara, ${ }^{2}$ \\ Jay Parikh,,2 Stephen Hightower,, ${ }^{1,2}$ Tracy Guo, ${ }^{2}$ Wolfgang Dillmann,, ${ }^{2}$ Young-Chul Kim, ${ }^{2}$ \\ Julieta Diaz-Juarez, ${ }^{2}$ and H. Kirk Hammond ${ }^{1,2}$
}

\begin{abstract}
Urocortin-2 (UCn2) peptide infusion increases cardiac function in patients with heart failure, but chronic peptide infusion is cumbersome, is costly, and provides only short-term benefits. Gene transfer would circumvent these shortcomings. We previously showed that a single intravenous (IV) injection of AAV8.UCn2 increases plasma $\mathrm{UCn} 2$ and left ventricular (LV) systolic and diastolic function for at least 7 months in normal mice. Here we test the hypothesis that IV delivery of AAV8.UCn2 increases function of the failing heart. Myocardial infarction (MI, by coronary ligation) was used to induce heart failure, which was assessed by echocardiography 3 weeks after MI. Mice with LV ejection fraction $(\mathrm{EF})<25 \%$ received IV delivery of AAV8.UCn2 $\left(5 \times 10^{11} \mathrm{gc}\right)$ or saline, and 5 weeks later echocardiography showed increased LV EF in mice that received $U C n 2$ gene transfer $(p=0.01)$. In vivo physiological studies showed a 2 -fold increase in peak rate of $\mathrm{LV}$ pressure development $(\mathrm{LV}+\mathrm{dP} / \mathrm{dt}$; $p<0.0001)$ and a 1.6-fold increase in peak rate of LV pressure decay ( $\mathrm{LV}-\mathrm{dP} / \mathrm{dt} ; p=0.0007)$, indicating increased LV systolic and diastolic function in treated mice. UCn2 gene transfer was associated with increased peak systolic $\mathrm{Ca}^{2+}$ transient amplitude and rate of $\mathrm{Ca}^{2+}$ decline and increased SERCA2a expression. In addition, UCn2 gene transfer reduced Thr286 phosphorylation of Cam kinase II, and increased expression of cardiac myosin light chain kinase, findings that would be anticipated to increase function of the failing heart. We conclude that a single IV injection of AAV8.UCn2 increases function of the failing heart. The simplicity of IV injection of a vector encoding a gene with beneficial paracrine effects to increase cardiac function is an attractive potential clinical strategy.
\end{abstract}

\section{Introduction}

C Ongestive heart failure (CHF) is associated with unacceptably high morbidity and mortality. Even with optimal medical and device management, $50 \%$ of class III and class IV CHF patients die within 4 years. In the United States, the prevalence for $\mathrm{CHF}$ is 6 million patients; 670,000 new cases are diagnosed annually. ${ }^{1}$ Because the prevalence of $\mathrm{CHF}$ is increasing and the outlook remains dismal, gene transfer is rational and may fulfill an unmet medical need.

Current methods of gene transfer for heart diseases include intramuscular (IM) injection into heart muscle and intracoronary delivery, which are cumbersome to apply. Gene transfer trials for heart disease have thus far been disappointing perhaps because of inadequate levels of gene expression in the heart. To circumvent this impediment, we have proposed a different approach: intravenous (IV) delivery of a vector encoding a transgene with paracrine activity affecting the heart. In this strategy, a peptide with beneficial cardiovascular effects is released to the circulation from distant sites after systemic delivery of a long-term expression vector encoding the peptide. This approach enables gene transfer via a simple IV injection during an office visit, circumvents the need for more invasive delivery methods, and potentially may give gene transfer for heart failure a much needed boost.

Clinical trials of systemic delivery of genes are underway for hemophilia $\mathrm{B}^{2,3}$ and $\alpha 1$-antitrypsin deficiency ${ }^{4}$ and others are in

\footnotetext{
${ }^{1}$ VA San Diego Healthcare System, San Diego, CA 92161.

${ }^{2}$ Department of Medicine, University of California-San Diego, San Diego, CA 92161.

*These two authors contributed equally to this work.
}

(c) N. Chin Lai et al. 2015; Published by Mary Ann Liebert, Inc. This Open Access article is distributed under the terms of the Creative Commons Attribution Noncommercial License (http://creativecommons.org/licenses/by-nc/4.0/) which permits any noncommercial use, distribution, and reproduction in any medium, provided the original author(s) and the source are credited. 
development. However, systemic delivery of vectors encoding peptides with beneficial paracrine activity has not been performed in clinical CHF trials, and is uncommon in preclinical studies. ${ }^{5,6}$ Intravenous infusion of potentially beneficial peptides such as urodilatin, ${ }^{7}$ relaxin- $2,{ }^{8}$ urocortin-2 (UCn2), ${ }^{9,10}$ and stresscopin $^{11}$ shows promise in clinical CHF trials, but gene transfer of these peptides has not been attempted.

Urocortins 1, 2, and 3 (38-41 amino acids) belong to the corticotropin-releasing factor (CRF) family. These peptides stimulate CRF receptors 1 and 2 (CRFR1 and CRFR2). UCn1 binds to CRFR1 and CRFR2, but UCn2 and UCn 3 exclusively bind to CRFR2, which is expressed in cardiac myocytes, vasculature, gut, brain, and skeletal muscle. ${ }^{12-14}$ Through selective CRFR2 activation, UCn2 mediates protean beneficial effects, including reduced renin-aldosterone activation, and is a potent inotrope with minimal effects on cardiac cAMP. ${ }^{15}$ In preclinical and clinical HF, peptide infusions of UCn2 or stresscopin, a related peptide, have shown favorable effects on left ventricular (LV) function. ${ }^{9-11,16}$

Since plasma half-life of UCn2 is $15 \mathrm{~min},{ }^{10}$ chronic infusion is required for sustained effects. The inconvenience, need for hospitalization and associated hazards, and the expense of therapeutic peptide infusions for CHF are considerable, and impede the broad use of these otherwise attractive peptides. The present study was conducted to address and resolve these shortcomings using $U C n 2$ gene transfer in a murine model of $\mathrm{CHF}$.

Adeno-associated virus (AAV) vectors enable prolonged transgene expression. For example, persistent transgene expression has been shown in nonhuman primates for sustained periods after $\mathrm{IM}^{17}$ or IV delivery of AAV vectors. ${ }^{18-20} \mathrm{We}$ have confirmed this in rats. ${ }^{6}$ Although recent clinical trials have found that some AAV serotypes incite immune responses after IM injection, ${ }^{21,22}$ newer generation AAV vectors (AAV5, $6,8,9$, rh-10) do not appear to have similar problems in nonhuman primates. ${ }^{19,20,23,24}$ IV AAV delivery is superior to IM vis-à-vis serum transgene levels, and AAV9 and AAV8 are superior to AAV5. ${ }^{25}$ Moreover, preexisting anti-AAV8 antibodies are not as prevalent in humans (19\%) as are other AAV serotypes, including AAV1 and AAV2 (50-59\%). ${ }^{26}$ These data suggest that IV AAV8 may be an attractive delivery route and vector to attain sustained increased levels of plasma UCn2. IV delivery of an AAV vector encoding a paracrine gene, as compared with IV peptide infusion, has the potential to circumvent infection and reduce repeated and prolonged hospital stays, thereby reducing costs. Systemic vector delivery may be an advantage in this approach-it provides the highest level of expression for any given AAV dose-by exploiting widespread distribution of the vector.

In a previous study we showed that a single IV injection of AAV8.UCn2 increases plasma $\mathrm{UCn} 2$ and increases LV systolic and diastolic function for at least 7 months in normal mice. ${ }^{27}$ The present study was conducted to test the hypothesis that IV delivery of AAV8.UCn2 will increase function of the failing heart.

\section{Methods}

\section{AAV8.UCn2 vector production}

A helper virus-free AAV8 vector encoding murine UCn2 driven by a chicken $\beta$-actin (CBA) promoter (AAV8.CBA .$U C n 2$; Fig. 1) was produced by transient transfection of
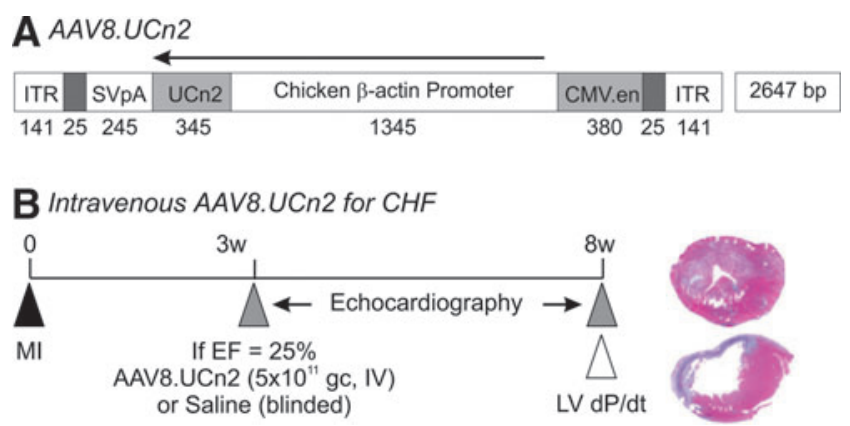

FIG. 1. AAV8.CBA.UCn2 map and experimental protocol. (A) AAV8.CBA.UCn2 vector map. CBA, chicken $\beta$-actin promoter; CMV.en, human cytomegalovirus enhancer; ITR, inverted terminal repeat; SVpA, polyA from SV40 viral genome; UCn2, urocortin-2. (B) Experimental protocol. Normal mice underwent myocardial infarction (MI, by proximal left coronary ligation) to induce $\mathrm{HF}$, which was assessed by echocardiography 3 weeks after MI. Mice with EF $<25 \%$ were then randomized to receive AAV8.UCn2 $\left(5 \times 10^{11} \mathrm{gc}\right.$, IV) or IV saline. Five weeks later, echocardiography was used to assess LV size and function. In vivo physiological studies were conducted to evaluate rates of LV pressure development $(\mathrm{LV}+\mathrm{dP} / \mathrm{dt})$ and decay $(\mathrm{LV}-\mathrm{dP} / \mathrm{dt})$, to assess LV systolic and diastolic function. Cross sections of LV (midpapillary level) show that the infarction is extensive (lower section), comprising the majority of the LV free wall, with only the interventricular septum spared. Data acquisition and analysis were blinded to group treatment. Color images available online at www.liebertpub.com/hum

HEK293T cells with the vector plasmid pRep2/Cap8 and pAd-Helper plasmid. ${ }^{28}$ Plasmid pRep2/Cap8 was obtained from the University of Pennsylvania Vector Core. Cell lysates prepared after $72 \mathrm{hr}$ of transfection were treated with benzonase and viruses were consolidated through $25 \%$ sucrosecushion ultracentrifugation. The pellets were resuspended for further purification of the virus through anion-exchange column chromatography (Q-Sepharose; GE Health Science) and concentrated by $25 \%$ sucrose-cushion ultracentrifugation. ${ }^{29,30}$ Subsequently, the pellets were resuspended in $10 \mathrm{~m} M$ Tris$\mathrm{HCl}$ (pH 7.9, $1 \mathrm{mM} \mathrm{MgCl}$, 3\% sucrose). Virus titers were determined by real-time qPCR with virus genome DNA prepared from purified virus.

\section{Heart failure model}

The Animal Use and Care Committee of the VA San Diego Healthcare System approved the studies. Two hundred thirty-one male C57BL/6J mice (Jackson Laboratories) aged 10-12 weeks, weighing $26.1 \pm 0.2 \mathrm{~g}$, were used. We used coronary occlusion to induce large anterior wall myocardial infarction (MI) and $\mathrm{CHF}$ as described in detail previously. ${ }^{31,32}$ MI size deliberately was large- $-50 \%$ of $\mathrm{LV}$, comprising most of the LV free wall (Fig. 1). Consequently, this model is associated with a high initial mortality. Of 231 mice that underwent coronary occlusion, 125 (54\%) died before randomization (AAV8.UCn2 or saline) primarily in the first few days after MI. An additional 45 mice (19\%) did not show sufficient LV dysfunction 3 weeks after MI to be randomized. Sixty-one mice (26\%) had sufficiently low LV ejection fractions $(\mathrm{EF}<25 \%)$ and were randomized, and 11 of these mice died before the final study 5 weeks after 
randomization: $4 \mathrm{UCn} 2$ (mortality 13\%) and 7 saline (mortality $23 \%$ ). The primary end point was LV function 5 weeks after IV delivery of AAV8.UCn2 versus saline in mice with severe heart failure (Fig. 1). Data were acquired and analyzed without knowledge of group identity.

\section{AAV8.UCn2 delivery}

Under anesthesia ( $1.5 \%$ isoflurane via nose cone), a small incision was made to expose the jugular vein for IV delivery of AAV8.UCn2 $\left(5 \times 10^{11}\right.$ genome copies [gc] in $\left.100 \mu \mathrm{l}\right)$ or a similar volume of saline (control).

\section{Effects of UCn2 gene transfer on heart rate and blood pressure}

These studies were conducted to assess the effects of $U C n 2$ gene transfer on heart rate and blood in unsedated mice with heart failure. Impaired LV EF was confirmed 3 weeks after MI, and mice received IV AAV8.UCn2 $\left(5 \times 10^{11}\right.$ gc) or saline. Systolic and diastolic blood pressure and heart rate were measured by tail cuff (Visitech Systems) in unsedated mice.

\section{Echocardiography}

Echocardiography was performed as previously described. ${ }^{33}$ Echocardiography was performed 3 weeks after MI to document reduced $\mathrm{LV}$ function $(\mathrm{EF}<25 \%)$ and to record $\mathrm{LV}$ chamber dimensions. Echocardiographic assessment was then repeated 5 weeks after randomization of mice to receive IV delivery of AAV8.UCn2 or saline.

\section{LV systolic and diastolic function}

Mice were anesthetized with sodium pentobarbital $(80 \mathrm{mg} / \mathrm{kg}$, ip) and a 1.4F conductance-micromanometer catheter (SPR 839; Millar Instruments) was advanced via the right carotid artery across the aortic valve and into the LV cavity. LV pressure was recorded and stored digitally for processing (IOX1.8; Emka Technologies) as previously reported. ${ }^{6}$ Subsequently, blood and tissue samples were obtained. After acquisition, the first derivatives of LV pressure development $(\mathrm{LV}+\mathrm{dP} / \mathrm{dt})$ and decline $(\mathrm{LV}-\mathrm{dP} / \mathrm{dt})$ were used to assess $\mathrm{LV}$ systolic and diastolic function. Data were acquired and analyzed without knowledge of group identity.

\section{Cardiac myocyte isolation}

Cardiac myocytes were isolated as previously described. ${ }^{33}$

\section{$\mathrm{Ca}^{2+}$ transients}

Cytosolic $\mathrm{Ca}^{2+}$ transients were measured using Indo- 1 as described previously ${ }^{27,34}$ with modifications. Cardiac myocytes were plated onto laminin-coated glass cover slips and loaded with indo-1/AM ( $3 \mu M$; Calbiochem) and dispersing agent, pluronic F-127 (0.02 mg/ml; Calbiochem), for $30 \mathrm{~min}$. Following dye loading, cover slips were mounted in a superfusion chamber, rinsed to remove excess indo-1-AM, and mounted on a Nikon Diaphot epifluorescence microscope equipped with a $40 \times$ objective interfaced to a Photon Technologies photometry system with the excitation wavelength set to $365 \mathrm{~nm}$ via a monochromator. Fluorescence emission was split and directed to two photomultiplier tubes through $20 \mathrm{~nm}$ band-pass filters centered at 405 and $485 \mathrm{~nm}$, respectively. The ratio F405/F485 represents a measure for $\left[\mathrm{Ca}^{2+}\right] i$. During these measurements, cardiac myocytes were superfused with $25 \mathrm{mM}$ HEPES ( $\mathrm{pH} 7.3$ ) containing $2 \mathrm{mM} \mathrm{CaCl}{ }_{2}$. Myocytes were field-stimulated at $0.3 \mathrm{~Hz}$. $\mathrm{Ca}^{2+}$ transients were recorded from 144 cardiac myocytes obtained from 6 hearts ( 3 per group). Diastolic and systolic intracellular $\mathrm{Ca}^{2+}$ levels were inferred from the basal and maximal indo- 1 ratio per cycle, respectively. Diastolic decay time (tau) was calculated from the normalized $\mathrm{Ca}^{2+}$ transient.

\section{Quantitative RT-PCR and immunoblotting}

$\mathrm{LV}$ and liver samples were collected and stored at $-80^{\circ} \mathrm{C}$ for quantitative RT-PCR and Western blotting.

Quantitative RT-PCR. LV and liver RNA was isolated using RNeasy mini kit (Qiagen) and qRT-PCR conducted as previously described ${ }^{27}$ under the following conditions: $5 \mathrm{~min}$ at $98^{\circ} \mathrm{C}, 40$ cycles of $30 \mathrm{~s}$ at $95^{\circ} \mathrm{C}, 30 \mathrm{~s}$ at $55^{\circ} \mathrm{C}$, and $30 \mathrm{~s}$ at $72^{\circ} \mathrm{C}$. RNA equivalents were normalized to simultaneously determined glyceraldehyde-3-phosphate dehydrogenase (GAPDH) mRNA levels in each sample. Primers are listed in Table 1.

Immunoblotting. Immunoblotting was performed as described previously. ${ }^{35}$ The following antibodies were used: cMLCK (Abgen/Thermo Scientific); p286 CamKII (Santa Cruz); phospho-PKA catalytic subunit, PKA catalytic subunit, troponin I (TnI), and 22/23-phospho-TnI (Cell Signaling Technology); phospholamban (PLB) (Thermo Fisher Scientific); Ser 16 and Thr 17-phospho-PLB (Badrilla, Ltd.); and SERCA2a (Enzo Life Sciences).

\section{Cyclic AMP and protein kinase A activity}

Transmural LV samples underwent cAMP measurement before and after stimulation with isoproterenol $(10 \mathrm{~m} M$, $10 \mathrm{~min})$ and NKH477 (10 $\mathrm{m} M, 10 \mathrm{~min})$, and cAMP was measured using the Biotrak Enzymeimmunoassay System (GE Healthcare) as previously described. ${ }^{36}$ PKA activity was determined as previously described. ${ }^{27}$ Cardiac myocytes underwent cAMP measurement before and after stimulation with isoproterenol $(10 \mu M, 10 \mathrm{~min})$ and $\mathrm{NKH} 477(10 \mu M$, $10 \mathrm{~min}$ ) and subsequently homogenized in buffer A, $20 \mathrm{mM}$ Tris- $\mathrm{HCl}$ ( $\mathrm{pH} 7.4), 0.5 \mathrm{~m} M$ EGTA, $0.5 \mathrm{~m} M$ EDTA, and protease inhibitor cocktail (Invitrogen), and centrifuged $\left(14,000 \times g, 5 \mathrm{~min}, 4^{\circ} \mathrm{C}\right)$. The supernatant was incubated with PKA biotinylated peptide substrate (SignaTECT cAMP-Dependent Protein Kinase Assay System; Promega) in the presence of $\left[\gamma-{ }^{32} \mathrm{P}\right] \mathrm{ATP}$. The ${ }^{32} \mathrm{P}$-labeled biotinylated substrate was recovered with a streptavidin matrix and the specific activity of PKA determined.

\section{Histology}

Samples of liver and transmural sections of the uninfarcted LV septum were formalin fixed and paraffin embedded. Five-micrometer sections were mounted and counterstained with hematoxylin and eosin and with Masson's trichrome. For quantitative assessment of LV fibrosis, images of a short-axis midwall LV ring were obtained with a 
TABle 1. Primers

\begin{tabular}{|c|c|c|}
\hline Gene & Forward & Reverse \\
\hline$A N F$ & 5'-CCTCGTCTTGGCCTTTTGG & 5'-CATCTTCTACCGGCATCTTC \\
\hline$\alpha-M H C$ & 5'AAAGGCTGAGAGGAACTACC & 5'-ACCAGCCTTCTCСТCTGC \\
\hline$\alpha-C d-a c t i n$ & 5'-GTGTTACGTCGCCCTTGATT & 5'-TGAAAGAGGGCTGGAAGAGA \\
\hline$\alpha-S K-a c t i n$ & 5'-GTGTCACCCACAACGTGC & 5'-AGGGCCACATAGCACAGC \\
\hline$\beta-M H C$ & 5'-GCTGAAAGCAGAAAGAGATTATC & 5'-TGGAGTTCTTCTCTTCTGGAG \\
\hline$B N P$ & 5'-GAAGTCCTAGCCAGTCTCC & 5'-CAGCTTGAGATATGTGTCACC \\
\hline Coll1 $\alpha 1$ & 5'-GCCAAGAAGACATCCCTGAAG & 5'-GGGTCCCTCGACTCCTAC \\
\hline Coll $3 \alpha 1$ & 5'-GCACAGCAGTCCAACGTAGA & 5'-TCTCCAAATGGGATCTCTGG \\
\hline$G A P D H$ & 5'-CATGTTCCAGTATGACTCCACTC & 5'-GGCCTCACCCCATTTGATGT \\
\hline$M E F 2$ & 5'-GAGCCTCATGAAAGCAGGAC & 5'-GAAGTTCTGAGGTGGCAAGC \\
\hline$M M P 2$ & 5'-GAGTTGCAACCTCTTTGTGC & 5'-CAGGTGTGTAACCAATGATCC \\
\hline$M M P 8$ & 5'-GACTCTGGTGATTTCTTGCTAAC & 5'-CACCATGGTCTCTTGAGACG \\
\hline$M M P 9$ & 5'-CGTCGTGATCCCCACTTACT & 5'-GAACACACAGGGTTTGCCTTC \\
\hline TIMP1 & 5'-GACAGCTTTCTGCAACTCGG & 5'-CTTGTGGACATATCCACAGAGG \\
\hline TIMP2 & 5'-GCAATGCAGACGTAGTGATCAG & 5'-ССТTСТTТССТССАACGTCC \\
\hline TIMP3 & 5'-CTTCTGCAACTCCGACATCG & 5'-CCTGTCAGCAGGTACTGG \\
\hline TIMP4 & 5'-CAAGGATATTCAGTATGTCTACACG & 5'-CTGGTGGTAGTGATGATTCAGG \\
\hline$U C n 2$ & 5'-АСТССТАТССССАССТТССА & 5'-AAGATCCGTAGGAGGCCAAT \\
\hline
\end{tabular}

ANF, atrial natriuretic peptide; BNP, brain natriuretic peptide; Coll, collagen; MEF2, myocyte enhancer factor-2; MMP, matrix metallopeptidase; TIMP, tissue inhibitor of metalloproteinases; UCn2, urocortin 2; $\alpha$-Cd-actin, alpha-cardiac actin; $\alpha$-MHC, alpha-myosin heavy chain; $\alpha$-SK-actin, alpha-skeletal actin; $\beta$-MHC, beta-myosin heavy chain.

Nikon Eclipse Ti-U microscope. Blinded analysis of the degree of fibrosis in the viable $\mathrm{LV}$ region (excluding the infarcted region) was conducted using NIS-Elements AR 3.10 software (Nikon Inc.). A similar analytical process was performed on fixed and counterstained liver samples.

\section{Statistical analysis}

Data represent mean $\pm \mathrm{SE}$; group differences were tested for statistical significance with ANOVA followed by Bonferroni $t$-test. Between-group comparisons were made using Student's $t$-test (unpaired, two-tailed). The null hypothesis was rejected when $p<0.05$.

\section{Results}

\section{Heart rate and blood pressure in unsedated mice}

No group differences were seen in heart rate or systolic, diastolic, or mean arterial blood pressure 5 weeks after $U C n 2$ gene transfer (Table 2), although heart rates tended to be quite high in the untreated group and closer to normal in mice that had received $U C n 2$ gene transfer.

\section{Urocortin 2 expression}

Five weeks after IV delivery of AAV8.UCn2 $\left(5 \times 10^{11} \mathrm{gc}\right.$; $n=6)$, UCn2 mRNA was increased 15,263-fold in liver $(p<0.0001)$ and 70-fold in LV $(p=0.03)$ versus endogenous UCn2 mRNA.

\section{Echocardiography}

Intravenous delivery of AAV8.UCn2 to mice with $\mathrm{HF}$ was associated with increased EF $(p=0.01)$, and velocity of circumferential fiber shortening was increased but did not reach statistical significance $(p=0.09)$. Mice that received AAV8.UCn2 also exhibited reductions in LV enddiastolic diameter (EDD; $p<0.001)$ and LV end-systolic diameter (ESD; $p=0.002)$. The saline-treated mice showed an $11 \%$ increase in LV EDD, while the UCn2-treated group showed a $2 \%$ decrease in LV EDD. Similarly, the saline group showed a $16 \%$ increase in LV ESD, while the UCn2 group experienced a $6 \%$ reduction. Although these changes in LV dimension are small, volume is a cubic function of dimension, so the changes are considerable - a calculated $64 \%$ increase in ESD (saline vs. UCn2) and a 46\% increase in EDD (saline vs. UCn2). Posterior and septal wall thickness showed no group differences (Table 3).

\section{LV systolic and diastolic function}

In vivo assessment of $\mathrm{LV}$ pressure development showed substantial increases in rates of $\mathrm{LV}$ pressure development $(\mathrm{LV}+\mathrm{dP} / \mathrm{dt} ; p<0.0001)$ and in $\mathrm{LV}$ relaxation $(\mathrm{LV}-\mathrm{dP} / \mathrm{dt}$; $p<0.0007$ ) (Fig. 2 and Table 4). There were no group differences in mean arterial pressure (Table 4). Heart rate during these studies, conducted under anesthesia, was somewhat

Table 2. Effects of $U C N 2$ Gene Transfer on Heart Rate and Blood Pressure in Mice with Heart Failure

\begin{tabular}{lrrr}
\hline & $H F(\mathrm{n})$ & $H F+\mathrm{UCn} 2(\mathrm{n})$ & $\mathrm{p}$ \\
\hline Heart rate, beats/min & $693 \pm 54(4)$ & $601 \pm 96(5)$ & 0.13 \\
Systolic pressure, mmHg & $123 \pm 23(5)$ & $105 \pm 17(5)$ & 0.20 \\
$\begin{array}{l}\text { Diastolic } \\
\quad \text { pressure, mmHg }\end{array}$ & $89 \pm 18(5)$ & $73 \pm 14(5)$ & 0.16 \\
$\begin{array}{l}\text { Mean arterial } \\
\quad \text { pressure, mmHg }\end{array}$ & $100 \pm 19(5)$ & $83 \pm 16(5)$ & 0.28 \\
\hline
\end{tabular}

The effects of UCn2 gene transfer on blood pressure and heart rate (HR) were assessed in unsedated mice with heart failure (HF) 5 weeks after $U C n 2$ gene transfer $\left(\mathrm{HF}+\mathrm{UCn} 2,5 \times 10^{11} \mathrm{gc}, \mathrm{IV}\right)$ or IV saline (HF). Systolic and diastolic blood pressure was measured by tail cuff and mean blood pressure calculated. No group differences were seen in heart rate or blood pressure. Values denote mean $\pm \mathrm{SE}$; $p$-values are from Student's $t$-test (unpaired, 2-tailed). 
Table 3. Echocardiography Before and After UCN2 Gene Transfer vs. Saline for HF

\begin{tabular}{|c|c|c|c|c|c|c|c|}
\hline & \multicolumn{3}{|c|}{$H F(12)$} & \multicolumn{3}{|c|}{$H F+U C n 2$} & \multirow[b]{2}{*}{$\mathrm{p}$} \\
\hline & $\begin{array}{l}3 \text { weeks } \\
\text { after } M I\end{array}$ & $\begin{array}{c}5 \text { weeks } \\
\text { after Saline }\end{array}$ & Post-Pre & $\begin{array}{l}3 \text { weeks } \\
\text { after } M I\end{array}$ & $\begin{array}{c}5 \text { weeks } \\
\text { after UCn2 }\end{array}$ & Post-Pre & \\
\hline HR (bpm) & $542 \pm 18$ & $513 \pm 13$ & $-29 \pm 21$ & $503 \pm 12$ & $525 \pm 12$ & $22 \pm 13$ & 0.045 \\
\hline $\mathrm{EDD}(\mathrm{mm})$ & $5.3 \pm 0.3$ & $5.9 \pm 0.3$ & $0.6 \pm 0.1$ & $5.3 \pm 0.3$ & $5.2 \pm 0.3$ & $-0.1 \pm 0.1$ & $<0.001$ \\
\hline $\mathrm{ESD}(\mathrm{mm})$ & $4.5 \pm 0.4$ & $5.2 \pm 0.4$ & $0.7 \pm 0.2$ & $4.7 \pm 0.4$ & $4.4 \pm 0.4$ & $-0.3 \pm 0.2$ & 0.002 \\
\hline $\mathrm{LV}$ EF $(\%)$ & $19 \pm 2$ & $12 \pm 1$ & $-7 \pm 2$ & $17 \pm 2$ & $20 \pm 4$ & $3 \pm 3$ & 0.01 \\
\hline $\mathrm{VCFc}(\mathrm{circ} / \mathrm{sec})$ & $3.3 \pm 0.9$ & $3.0 \pm 0.8$ & $-0.3 \pm 0.6$ & $3.5 \pm 0.7$ & $4.7 \pm 0.8$ & $1.2 \pm 0.6$ & 0.09 \\
\hline $\mathrm{PW}$ Th $(\mathrm{mm})$ & $0.5 \pm 0.03$ & $0.5 \pm 0.03$ & $-0.05 \pm 0.03$ & $0.5 \pm 0.03$ & $0.5 \pm 0.03$ & $-0.01 \pm 0.02$ & 0.20 \\
\hline IVS Th (mm) & $0.5 \pm 0.04$ & $0.5 \pm 0.04$ & $0.01 \pm 0.02$ & $0.5 \pm 0.04$ & $0.5 \pm 0.05$ & $-0.02 \pm 0.04$ & 0.43 \\
\hline
\end{tabular}

bpm, beats per minute; EDD, LV end-diastolic diameter; ESD, LV end-systolic diameter; HF, heart failure; HR, heart rate; IVS Th, interventricular wall thickness at end-diastole; LV EF, left ventricular ejection fraction; Post-Pre, the value 5 weeks after saline or UCn2 gene transfer minus the value before; PW Th, posterior wall thickness at end-diastole; UCn2, urocortin-2; VCFc, velocity of circumferential fiber shortening (corrected for heart rate).

$p$-Values from Student's $t$-test (paired data, 2-tailed) for group difference in change, Post-Pre.

higher in mice that had received $U C n 2$ gene transfer, but the difference did not reach statistical significance.

\section{Cytosolic $\mathrm{Ca}^{2+}$ transients and related genes}

Basal $\mathrm{Ca}^{2+}$ released (systolic-diastolic $\mathrm{Ca}^{2+}$ ) was increased in cardiac myocytes from heart failure mice that had received $U C n 2$ gene transfer ( $p=0.0001$; Fig. $3 \mathrm{~A}$ and $\mathrm{B})$. $U C n 2$ gene transfer was also associated with a reduced $\mathrm{Ca}^{2+}$ decline time $\left(t_{1 / 2}\right.$, Tau $)$ in cardiac myocytes from mice with heart failure 5 weeks after $U C n 2$ gene transfer $p=0.001$; Fig. 3C and D). Increased UCn2 was associated with increased expression of SERCA2a mRNA and protein in normal and failing LV (Fig. 3E). However, no group differences were seen in LV protein expression and phosphorylation of PLB or TnI (data not shown).
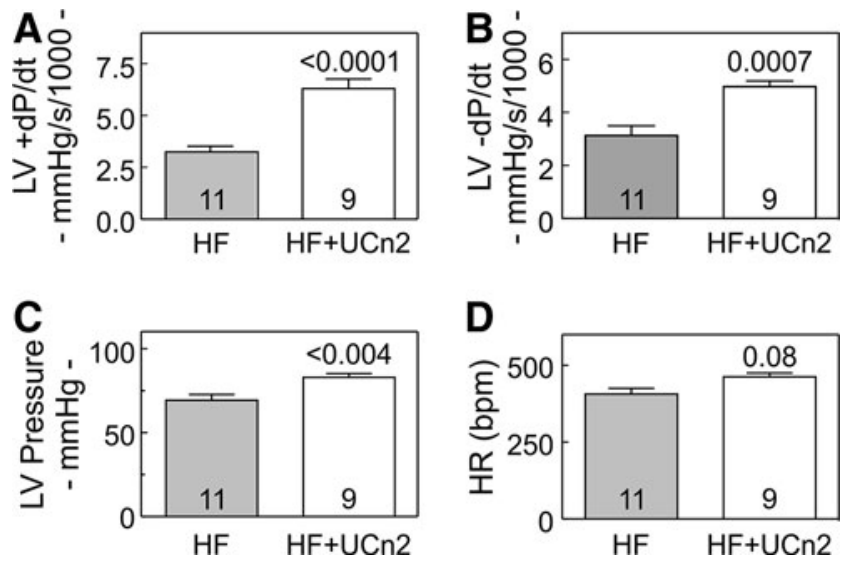

FIG. 2. LV function in vivo. (A and B) Five weeks after AAV8.UCn2 $\left(5 \times 10^{11} \mathrm{gc}, \mathrm{IV}\right)$ or saline (HF) infusion, in vivo studies were performed to measure the rate of $\mathrm{LV}$ pressure development: $\mathrm{LV}+\mathrm{dP} / \mathrm{dt}(\mathbf{A})$ and decay $\mathrm{LV}-\mathrm{dP} /$ dt (B). AAV8.UCn2 increased LV + dP/dt and LV - dP/dt 5 weeks after gene transfer, indicating that UCn2 gene transfer increases LV systolic function. (C and D) Heart rate tended to be higher (D). LV-developed pressure was increased by $U C n 2$ gene transfer $(\mathbf{C})$. Studies were performed without knowledge of group identity. $p$-Values are from Student's $t$-test (unpaired, 2-tailed). Data represent mean \pm $\mathrm{SE}$, and numbers in bars denote group size.

\section{Cyclic AMP and PKA activity}

LV samples and cardiac myocytes isolated from hearts of both groups showed no differences in cAMP or PKA activity (Fig. 4). Cyclic AMP production and PKA activity were assessed before and after stimulation with isoproterenol or NKH477, a water-soluble forskolin analog that stimulates adenylate cyclase independently of $\beta$-adrenergic receptors. No group differences were seen in basal, Iso, or NKH477-stimulated cAMP production (Fig. 4A) or in PKA activity (Fig. 4B). Expression of PKA family proteins (catalytic $\alpha$ unit and regulatory $\alpha$ and $\beta$ subunits and their phosphorylation) was not altered (data not shown).

\section{CamKII and cMLCK}

To seek mechanisms to explain increased function of the failing heart evoked by $U C n 2$ gene transfer, we measured LV expression and phosphorylation of calcium/calmodulin-dependent protein kinase II (CamKII) and expression of cardiac myosin light chain kinase 3 (cMLCK). CamKII phosphorylation at Ser286 was reduced in LV samples from HF mice after $U C n 2$ gene transfer (47\% reduction, $p=0.04$; Fig. 4C), although total CamKII protein expression showed no group difference. Seeking alterations in myofilament sensitivity to $\mathrm{Ca}^{2+}$, we assessed LV cardiac myosin light chain kinase 3 (cMLCK) expression after UCn2 gene transfer, finding a 1.6fold increase $(p<0.04)$ (Fig. 4D).

Table 4. Physiological Data

\begin{tabular}{lccc}
\hline & Saline (11) & $\mathrm{UCn} 2(9)$ & $\mathrm{p}$ \\
\hline $\mathrm{LVP}(\mathrm{mmHg})$ & $68 \pm 3$ & $83 \pm 2$ & $<0.004$ \\
$\mathrm{LV}+\mathrm{dP} / \mathrm{dt}(\mathrm{mmHg} / \mathrm{s})$ & $3225 \pm 287$ & $6354 \pm 451$ & $<0.0001$ \\
$\mathrm{LV}-\mathrm{dP} / \mathrm{dt}(\mathrm{mmHg} / \mathrm{s})$ & $-3127 \pm 370$ & $4974 \pm 215$ & $<0.0007$ \\
$\mathrm{MAP}(\mathrm{mmHg})$ & $56 \pm 3$ & $63 \pm 3$ & 0.10 \\
$\mathrm{HR}(\mathrm{bpm})$ & $404 \pm 23$ & $461 \pm 18$ & 0.08 \\
\hline
\end{tabular}

$\mathrm{HR}$, heart rate; $\mathrm{LV}$, left ventricle; LVP, left ventricular developed pressure; MAP, mean arterial pressure; UCn2, urocortin-2 gene transfer.

Three weeks after myocardial infarction, mice received intravenous saline or AAV8.UCn $2\left(5 \times 10^{11} \mathrm{gc}\right)$. Mice underwent physiological studies 5 weeks later. Values represent mean \pm SE. $p$-Values are from Student's $t$-test (unpaired, 2-tailed). 
A

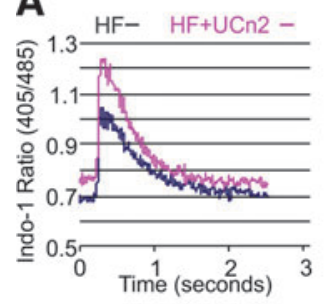

C

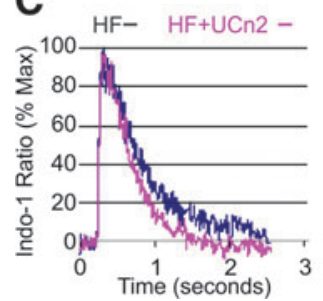

B

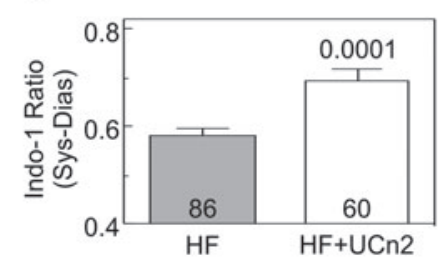

D

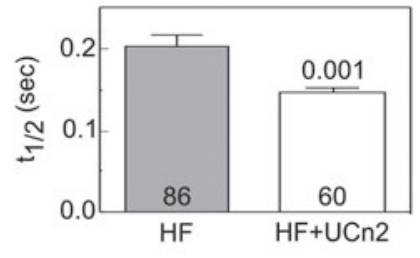

E
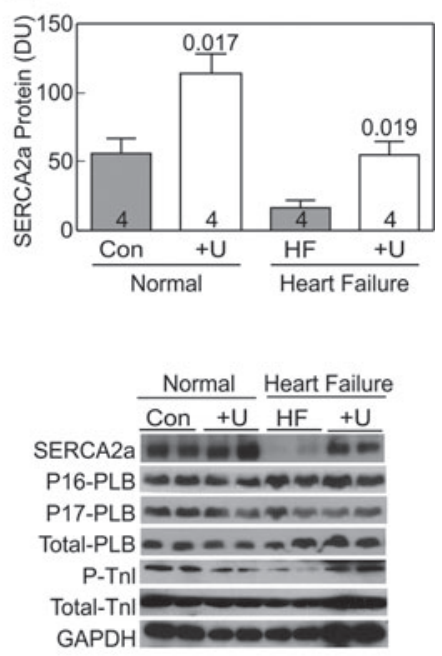

FIG. 3. Cytosolic $\mathrm{Ca}^{2+}$ transients in cardiac myocytes from mice with heart failure (HF) 5 weeks after IV AAV8.UCn2 $(\mathrm{HF}+\mathrm{UCn} 2)$ or IV saline. (A and B) Basal $\mathrm{Ca}^{2+}$ released (systolic-diastolic $\mathrm{Ca}^{2+}$ ) was increased in cardiac myocytes from $\mathrm{HF}+\mathrm{UCn} 2$ mice $(p=0.0001)$. (A) Representative Indo-1 $\mathrm{Ca}^{2+}$ transient recordings from one heart in each group showed increased peak $\mathrm{Ca}^{2+}$ in cardiac myocytes isolated from mice with heart failure 5 weeks after UCn2 gene transfer. (B) Summary data from three mice per group are shown. (C and D) Time to $\mathrm{Ca}^{2+}$ decline $\left(t_{1 / 2}\right.$, Tau) was shortened in cardiac myocytes from mice with heart failure 5 weeks after UCn2 gene transfer. (C) Representative normalized Ca ${ }^{2+}$ transients from cardiac myocytes from one heart in each group. (D) Summary data from three mice per group are shown. For (A) and (C), each curve is the average of 30 cardiac myocytes from one heart from each group. For (B) and (D), summary data from 3 animals per group include analysis of 146 individual cardiac myocytes (86, saline; 60, AAV8.UCn2). For (B) and (D), bars denote mean + SE; numbers in bars denote number of cardiac myocytes; numbers above bars indicate $p$-values from Student's $t$-test (unpaired, 2-tailed). (E) Summary (top panel) of immunoblotting data (bottom panel) indicates that $U C n 2$ gene transfer increased SERCA2a protein in LV from normal mice and from mice with heart failure. Expression and phosphorylation of phospholamban (PLB) and troponin I (TnI) were not affected. Bars denote mean + SE; numbers in bars denote group size; numbers above bars from Student's $t$-test (unpaired, 2-tailed vs. control).

A

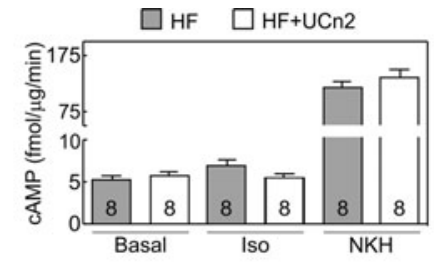

C

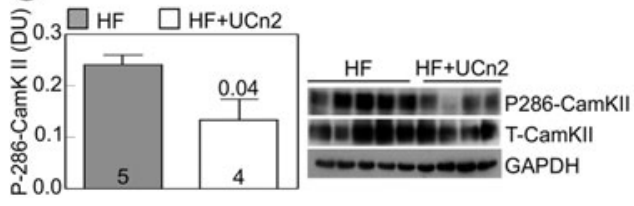

B

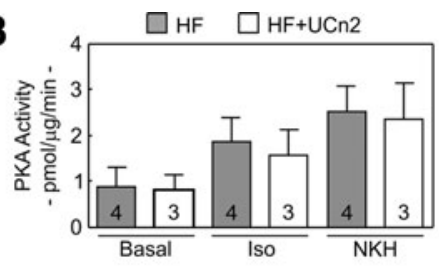

D

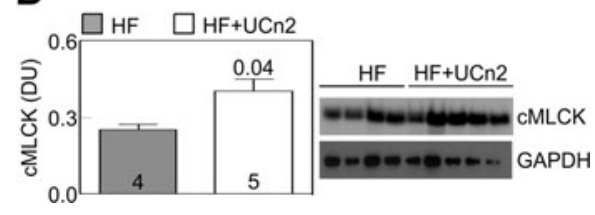

FIG. 4. Cardiac myocyte cAMP-PKA signaling. LV samples (A, C, D) or cardiac myocytes (B) were obtained from mice with heart failure (HF) and from mice with HF that had received AAV8.UCn2 (UCn2). Cyclic AMP and PKA activity were assessed in the unstimulated (basal) state and after stimulation with isoproterenol (Iso, $10 \mu M$, 10 min) and, in separate experiments, NKH477 (NKH, $10 \mu M, 10 \mathrm{~min}$ ), a water-soluble forskolin analog that stimulates adenylate cyclase independent of $\beta$-adrenergic receptors. Numbers in bars denote group size. (A) cAMP production: no group differences were seen in basal, Iso, or NKH477-stimulated cAMP production. (B) PKA activity: no group differences were seen in basal, Iso, or NKH477-stimulated conditions. (C) CamK II expression and phosphorylation: UCn2 gene transfer was associated with reduced Thr286 phosphorylation of CamK II (left panel, normalized to GAPDH). Total CamK II was unchanged. (D) Cardiac myosin light chain kinase: $U C n 2$ gene transfer was associated with increased cardiac myosin light chain kinase (cMLCK) protein (left panel, normalized to GAPDH). In all graphs, bars denote mean + SE; numbers in bars denote group size, numbers above bars from Student's $t$-test (unpaired, 2-tailed vs. control groups). 
TABle 5. Necropsy

\begin{tabular}{lccc}
\hline & Saline (17) & UCn2 (17) & $\mathrm{p}$ \\
\hline BW, g & $30 \pm 1$ & $31 \pm 1$ & $<0.17$ \\
LV, mg & $154 \pm 7$ & $139 \pm 5$ & 0.095 \\
LV/BW, mg/g & $5.1 \pm 0.2$ & $4.5 \pm 0.1$ & 0.01 \\
Liver, mg & $1489 \pm 53$ & $1405 \pm 43$ & $<0.2$ \\
Lung, mg & $212 \pm 19$ & $213 \pm 13$ & 0.97 \\
\hline
\end{tabular}

BW, body weight; LV, left ventricle; UCn2, urocortin-2 gene transfer.

Three weeks after myocardial infarction, mice received intravenous saline or AAV8.UCn $2\left(5 \times 10^{11} \mathrm{gc}\right)$. Mice were killed 6 weeks later and necropsy conducted. Values represent mean \pm SE. $p$-Values are from Student's $t$-test (unpaired, 2-tailed).

\section{Necropsy}

Liver, lung, and body weights showed no group differences. UCn2 gene transfer tended to reduce LV weight, and LV-tobody weight ratio was reduced $(12 \%$ reduction; $p=0.01)$ (Table 5).

\section{Markers of stress, inflammation, and tissue injury}

The expression of several markers of LV stress, inflammation, and tissue injury was examined using RT-PCR. HF altered the expression of most of these genes (Table 6). Increased $U C n 2$ expression did not influence alterations associated with HF. However, in normal mice, increased $U C n 2$ expression was associated with reduced expression of ANF $(p=0.007)$, BNP $(p=0.01), \beta$-MyHC, and $\alpha$-SK-actin $(p=0.03)$.

\section{LV and liver histology}

Hematoxylin and eosin staining of samples of liver and LV showed no evidence of group differences (data not shown). Masson's trichrome staining revealed no group differences in fibrosis in liver $(p=0.79)$.

\section{Discussion}

The most important finding in this study is that a single IV injection of AAV8.UCn2 increased function of the failing heart, demonstrating the feasibility and effectiveness of IV delivery of a long-term expression vector encoding a peptide with beneficial paracrine effects to treat heart failure.

Two measures of cardiac function confirmed increased LV function 5 weeks after IV AAV8.UCn2 delivery to animals with severely dysfunctional left ventricles. Echocardiography showed increases in LV EF, and reductions in LV volumes (Table 3). Second, UCn2 gene transfer increased peak $\mathrm{LV}+\mathrm{dP} / \mathrm{dt}$, indicating enhanced $\mathrm{LV}$ contractile function, and reduced $\mathrm{LV}-\mathrm{dP} / \mathrm{dt}$, indicating enhanced LV diastolic function (Table 4 and Fig. 2).

Although the absolute degree of LV EF change was only $8 \%$ units (HF: $12 \% \pm 1 \%$; $\mathrm{HF}+\mathrm{UCn} 2: 20 \% \pm 4 \%$ ), the relative increase was $67 \%$. The small absolute change reflects the large size of the infarction - the mean prerandomization LV EFs were $\leq 20 \%$ in both groups. Despite such large infarctions, $U C n 2$ gene transfer attenuated LV chamber dilation and increased EF, while saline-treated mice showed progressive $\mathrm{LV}$ chamber dilation and further deterioration of LV EF. One would not expect UCn2 gene transfer to remedy the problems associated with such a large area of scar, representing virtually the entirety of the LV free wall. The cardiac benefits of $U C n 2$ gene transfer would be anticipated to be limited to the viable portion of the LV, which, in the current model, represents the interventricular septum. EF in this setting may underestimate the benefits on LV function, especially since we observed dyskinesia of the infarcted

TABLE 6. MRNA EXPRESSION IN LEFT VENTRICLE

\begin{tabular}{|c|c|c|c|c|c|c|c|}
\hline \multirow[b]{2}{*}{ Gene } & \multicolumn{2}{|c|}{ Normal } & \multicolumn{2}{|c|}{$H F$} & \multirow[b]{2}{*}{ Interaction } & \multirow[b]{2}{*}{ UCn2 effect } & \multirow[b]{2}{*}{ HF effect } \\
\hline & Control & $U C n 2$ & Control & $U C n 2$ & & & \\
\hline$A N F$ & $100 \pm 17$ & $38 \pm 7$ & $2393 \pm 591$ & $2458 \pm 728$ & ns & ns & 0.0001 \\
\hline$\alpha-M H C$ & $100 \pm 10$ & $83 \pm 26$ & $837 \pm 90$ & $714 \pm 76$ & ns & ns & 0.0001 \\
\hline$\alpha-C d-a c t i n$ & $100 \pm 7$ & $164 \pm 70$ & $1160 \pm 94$ & $1368 \pm 134$ & ns & ns & 0.0001 \\
\hline$\alpha-s k$-actin & $100 \pm 32$ & $18 \pm 4$ & $56 \pm 12$ & $51 \pm 14$ & 0.05 & 0.03 & ns \\
\hline$\beta-M H C$ & $100 \pm 33$ & $11 \pm 3$ & $104 \pm 23$ & $74 \pm 20$ & ns & 0.016 & ns \\
\hline$B N P$ & $100 \pm 16$ & $44 \pm 9$ & $484 \pm 098$ & $525 \pm 152$ & ns & ns & 0.0001 \\
\hline$M M P 2$ & $100 \pm 9.5$ & $102 \pm 14$ & $707 \pm 304$ & $601 \pm 41$ & ns & ns & 0.002 \\
\hline$M M P 8$ & $100 \pm 38$ & $68 \pm 9.6$ & $96 \pm 36$ & $90 \pm 50$ & ns & ns & ns \\
\hline$M M P 9$ & $100 \pm 44$ & $68 \pm 2.3$ & $57 \pm 20$ & $44 \pm 21$ & ns & ns & ns \\
\hline TIMP1 & $100 \pm 47$ & $69 \pm 6$ & $250 \pm 62$ & $341 \pm 49$ & ns & ns & 0.0002 \\
\hline TIMP2 & $100 \pm 7$ & $122 \pm 16$ & $500 \pm 65$ & $719 \pm 106$ & ns & ns & 0.0001 \\
\hline TIMP3 & $100 \pm 13$ & $52 \pm 4$ & $207 \pm 42$ & $269 \pm 43$ & ns & ns & 0.0001 \\
\hline TIMP4 & $100 \pm 22$ & $86 \pm 16$ & $239 \pm 50$ & $164 \pm 21$ & ns & ns & 0.002 \\
\hline Coll1 $\alpha 1$ & $100 \pm 10$ & $152 \pm 7$ & $183 \pm 45$ & $257 \pm 38$ & ns & ns & 0.005 \\
\hline Coll3 $3 \alpha 1$ & $100 \pm 11$ & $140 \pm 17$ & $281 \pm 80$ & $376 \pm 62$ & ns & ns & 0.0006 \\
\hline$M E F 2$ & $100 \pm 9$ & $132 \pm 78$ & $1486 \pm 174$ & $1682 \pm 155$ & ns & ns & 0.0001 \\
\hline
\end{tabular}

ANF, atrial natriuretic peptide; BNP, brain natriuretic peptide; Coll, collagen; MEF2, myocyte enhancer factor-2; MMP, matrix metallopeptidase; TIMP, tissue inhibitor of metalloproteinases; $\alpha$-Cd-actin, $\alpha$-cardiac actin; $\alpha$-MHC, $\alpha$-myosin heavy chain; $\alpha$-SK-actin, $\alpha$-skeletal actin; $\beta$-MHC, $\beta$-myosin heavy chain.

RT-PCR detection of gene expression in LV tissues of normal and HF mice. RNA equivalents were normalized to simultaneously determined glyceraldehyde-3-phosphate dehydrogenase (GAPDH) mRNA levels in each sample and data are normalized to control in normal LV. 
wall during ejection. Assessment of LV contractile function using peak $\mathrm{LV}+\mathrm{dP} / \mathrm{dt}$ reveals a larger absolute increase in LV function - an increase of $3129 \mathrm{mmHg} / \mathrm{sec}$ in peak LV $+\mathrm{dP} / \mathrm{dt}$, and a $1847 \mathrm{mmHg} / \mathrm{sec}$ increase in peak $-\mathrm{dP} / \mathrm{dt}$ conferred by $U C n 2$ gene transfer. These represent a 2 -fold increase in peak $\mathrm{LV}+\mathrm{dP} / \mathrm{dt}$, and a 1.6-fold increase in peak $-\mathrm{dP} / \mathrm{dt}$. A doubling of peak $\mathrm{LV}+\mathrm{dP} / \mathrm{dt}$ in clinical heart failure would normalize LV contractile function. ${ }^{37,38}$

Heart rate and blood pressure in the unsedated state are not affected by IV delivery of AAV8.UCn2 despite sustained high levels of transgene UCn2 in normal mice ${ }^{27}$ or in mice with $\mathrm{CHF}$, as shown in the current study. Similarly, in clinical trials of peptide infusions of UCn2 and stresscopin (similar to UCn3), the rate-pressure product is unchanged. ${ }^{9-11}$ One would, therefore, not anticipate an increase in cardiac metabolic demands associated with $U C n 2$ gene transfer, but more direct metabolic studies must be performed to know this with certainty.

The present study focused on the feasibility and physiological consequences of IV delivery of AAV8.UCn2 in the setting of a severely compromised and failing heart, and we found a pronounced positive effect. The mechanisms by which $U C n 2$ gene transfer evoked beneficial physiological changes, although not the primary focus of the present study, were also examined.

For example, we found that $U C n 2$ gene transfer was associated with (1) increased peak systolic $\mathrm{Ca}^{2+}$ transient amplitude and increased rate of $\mathrm{Ca}^{2+}$ decline in cardiac myocytes isolated from HF mice (Fig. 3A-D), and (2) increased SERCA2a expression (Fig. 3E) as we previously reported in mice with normal hearts. ${ }^{27}$ Increased LV SERCA2a expression provides a mechanism by which LV contractile function and relaxation would be increased, as was observed (Fig. 2). SERCA2a returns cytosolic $\mathrm{Ca}^{2+}$ to the sarcoplasmic reticulum. An increased amount of SERCA2a would be anticipated to yield a more rapid cytosolic $\mathrm{Ca}^{2+}$ decline, which is what we found (Fig. 3C and $\mathrm{D})$, and consequently to increase the rate of $\mathrm{LV}$ pressure decline ( $\mathrm{LV}-\mathrm{dP} / \mathrm{dt}$ ), as we also found (Fig. 2B).

In addition, we found alterations in $\mathrm{LV}$ expression of two additional proteins that are likely to have been of mechanistic importance in the observed beneficial effects of $U C n 2$ gene transfer on function of the failing LV: reduced Thr286 phosphorylation of $\mathrm{Ca}^{2+} /$ calmodulin-dependent kinase II (CaMKII), and increased LV expression of cardiac myosin light chain kinase (cMLCK) (Fig. 4).

\section{CaMKII Thr286 phosphorylation}

Our data show that $U C n 2$ gene transfer was associated with reduced Thr286 phosphorylation of CaMKII (Fig. 4C). CaMKII expression and activation are important determinants of cardiac function. ${ }^{39}$ For example, cardiac-directed expression of CaMKII results in heart failure in mice. ${ }^{40}$ Others have shown increased CaMKII activity and expression in MI-induced heart failure in mice. ${ }^{41}$ The clinical relevance of these findings was demonstrated recently by the demonstration that inhibition of LV CaMKII increases function of the failing human heart. ${ }^{42}$ Although we speculate that reduced Thr286 phosphorylation of CaMKII may have been important mechanistically in the observed increase in LV function, we were unable to determine the pathway by which increased UCn2 reduces Thr286 CaMKII phosphorylation, which will require focused studies in cultured cardiac myocytes that are underway.

\section{Cardiac myosin light chain kinase}

We found increased cardiac myosin light chain kinase (cMLCK) expression associated with UCn2 gene transfer (Fig. 4D). Phosphorylation of cardiac myosin light chain $2 \mathrm{v}$ by cMLCK increases the rate of cross-bridge recruitment in cardiac myocytes and influences contractile function. ${ }^{4,44}$ Increased levels cMLCK are associated with increased LV function in the setting of MI-induced heart failure. ${ }^{45}$ In contrast, the deletion of cMLCK reduces cardiac performance. ${ }^{46}$ Sadly, there is no antibody available to assess myosin light chain $2 \mathrm{v}$ phosphorylation, and so the biological importance of the increase in cMLCK associated with $U C n 2$ gene transfer in the present study must remain speculative.

$U C n 2$ gene transfer was associated with a doubling in the peak rate of LV pressure development $(\mathrm{LV}+\mathrm{dP} / \mathrm{dt}$; Table 4 and Fig. 2). This finding was supported by evaluation of LV dimension and function by echocardiography (Table 3), enhanced $\mathrm{Ca}^{2+}$ handling (Fig. 3), and signaling changes in $\mathrm{LV}$ predicted to increase contractile function, including increased SERCA2a protein expression (Figs. 3 and 4). Because of the consistency of these findings, which reverberated from isolated cardiac myocytes to in vivo physiology, we were less concerned by the absence of group differences in BNP and ANF mRNA in LV (Table 6). Perhaps plasma levels or BNP/ANF expression in LA would have revealed group differences that LV mRNA levels missed. It is also possible that despite increased LV contractile function there was sufficient persistent chamber dilation-owing to infarction of the entire LV free wall- to provide ongoing stimulation of ANF and BNP expression.

We saw no group difference in lung or liver weight (Table 5). Liver weights were not increased in mice with heart failure compared with normal mice, ${ }^{27}$ and so, despite severe LV failure, there is no liver congestion. Whether this is unique to MI-induced $\mathrm{CHF}$ in mice is unknown. Lung weights increased by $23 \%$ versus normal age-matched mice, ${ }^{27}$ but did not show a group difference. We speculate that despite a doubling of LV contractile function (peak $+\mathrm{dP} / \mathrm{dt}$ ) conferred by UCn2 gene transfer (Table 4 and Fig. 2), there may have been persistent left-sided congestion 5 weeks after treatment.

\section{Clinical application}

Intravenous delivery of AAV8 enables transfection of many organs and is especially effective in liver, skeletal muscle, and heart. ${ }^{47}$ These organs, because they comprise an enormous mass of tissue and therefore can release abundant transgene $\mathrm{UCn} 2$, will enable us to reduce the vector dose. Indeed, a vector dose 10 -fold lower $\left(5 \times 10^{10}\right.$ gc per mouse or $2 \times 10^{12} \mathrm{gc} / \mathrm{kg}$ ) is still effective in increasing $\mathrm{LV}+\mathrm{dP} /$ dt. ${ }^{27} \mathrm{~A}$ dose of $2 \times 10^{12} \mathrm{gc} / \mathrm{kg}$ of AAV8 encoding human factor IX was delivered intravenously safely and effectively in a clinical trial in subjects with hemophilia B. ${ }^{2}$

An additional feature to consider in translating our findings to clinical applications is the use of a regulated expression system, 5,6 which would enable turning UCn2 expression on or off at will. We have designed such AAV8 
vectors using tetracycline and rapamycin regulation systems and are conducting preclinical studies with these regulated expression vectors.

$\mathrm{LV} \mathrm{Ca}{ }^{2+}$ handling is different in humans than in mice, ${ }^{48}$ but peptide infusions of UCn2 or stresscopin (similar to $\mathrm{UCn} 3$ ) in patients with $\mathrm{HF}$ increases $\mathrm{LV}$ function. ${ }^{9-11}$ Whether this is through $\mathrm{Ca}^{2+}$ handling is unknown because $\mathrm{Ca}^{2+}$ transients and $\mathrm{Ca}^{2+}$ handling proteins have not been assessed in cardiac myocytes or myocardium before and after UCn2 peptide infusions in humans.

Finally, now that we have demonstrated that $U C n 2$ gene transfer increases function of the severely failing heart, it will be important to determine how long the effect persists and whether it reduces mortality. Such studies using a less severe model of $\mathrm{CHF}$ with better long-term survival are planned.

\section{Conclusions}

A single IV injection of AAV8.UCn2 increases both systolic and diastolic function of the severely failing heart. Systemic delivery of the vector ensures that the transgene is expressed in the heart, but also is continuously released into the circulation, thereby providing sustained benefits that would otherwise not be possible. Other theoretical advantages of gene transfer as compared with IV infusion of paracrineacting peptides include reduction in catheter-based infections, no need for hospitalization, and reduced costs. Whether this strategy will be effective in increasing function of the failing heart in clinical settings will require additional studies.

\section{Acknowledgments}

This work was supported by National Institutes of Health grants (P01 HL66941, HL088426, HL081741, and HL107200) and Merit grants from the Department of Veteran's Affairs (1101BX001515 and 1101bBX000783).

\section{Author Disclosure Statement}

H.K.H. is founder, unpaid consultant, and equity holder of Renova Therapeutics. Renova did not fund the work and was not involved in its planning, interpretation, or writing. None of the other authors have disclosures.

\section{References}

1. Roger VL, Go AS, Lloyd-Jones DM, et al. Heart disease and stroke statistics-2012 update: a report from the American Heart Association. Circulation 2012;125:e2-e220.

2. Nathwani AC, Tuddenham EGD, Rangarajan S, et al. Adenovirus-associated virus vector-mediated gene transfer in hemophilia B. N Engl J Med 2011;365:2357-2365.

3. Buchlis G, Podsakoff GM, Radu A, et al. Factor IX expression in skeletal muscle of a severe hemophilia B patient 10 years after AAV-mediated gene transfer. Blood 2012;119:3038-3041.

4. Flotte TR, Trapnell BC, Humphries M, et al. Phase 2 clinical trial of a recombinant adeno-associated viral vector expressing $\alpha 1$-antitrypsin: interim results. Hum Gene Ther 2011;22:1239-1247.

5. Rivera VM, Ye X, Courage NL, et al. Long-term regulated expression of growth hormone in mice after intramuscular gene transfer. Proc Natl Acad Sci USA 1999;96:8657-8662.
6. Lai NC, Tang T, Gao MH, et al. Improved function of the failing rat heart by regulated expression of insulin-like growth factor I via intramuscular gene transfer. Hum Gene Ther 2012;23:255-261.

7. Mitrovic V, Seferovic PM, Simeunovic D, et al. Haemodynamic and clinical effects of ularitide in decompensated heart failure. Eur Heart J 2006;27:2823-2832.

8. Teerlink JR, Cotter G, Davison BA, et al. Serelaxin, recombinant human relaxin-2, for treatment of acute heart failure (RELAX-AHF): a randomised, placebo-controlled trial. Lancet 2013;381:29-39.

9. Chan WY, Frampton CM, Crozier IG, et al. Urocortin-2 infusion in acute decompensated heart failure: findings from the UNICORN study (urocortin-2 in the treatment of acute heart failure as an adjunct over conventional therapy). J Am Coll Cardiol Heart Fail 2013;1:433-441.

10. Davis ME, Pemberton CJ, Yandle TG. Urocortin 2 infusion in human heart failure. Eur Heart J 2007;28:2589-2597.

11. Gheorghiade M, Greene SJ, Ponikowski P, et al. Haemodynamic effects, safety, and pharmacokinetics of human stresscopin in heart failure with reduced ejection fraction. Eur J Heart Fail 2013;15:679-689.

12. Wiley KE, Davenport AP. CRF2 receptors are highly expressed in the human cardiovascular system and their cognate ligands urocortins 2 and 3 are potent vasodilators. Br J Pharmacol 2004;143:508-514.

13. Davidson SM, Yellon DM. Urocortin: a protective peptide that targets both the myocardium and vasculature. Pharmacol Rep 2009;61:172-182.

14. Davidson SM, Rybka AE, Townsend PA. The powerful cardioprotective effects of urocortin and the corticotropin releasing hormone $(\mathrm{CRH})$ family. Biochem Pharmacol 2009;77:141-150.

15. Bale TL, Hoshijima M, Gu Y, et al. The cardiovascular physiologic actions of urocortin II: acute effects in murine heart failure. Proc Natl Acad Sci USA 2004;101:36973702.

16. Rademaker MT, Charles CJ, Ellmers LJ, et al. Prolonged urocortin 2 administration in experimental heart failure: sustained hemodynamic, endocrine, and renal effects. Hypertension 2011;57:1136-1144.

17. Rivera VM, Gao GP, Grant RL, et al. Long-term pharmacologically regulated expression of erythropoietin in primates following AAV-mediated gene transfer. Blood 2005;105:1424-1430.

18. Nathwani AC, Gray JT, McIntosh J, et al. Safe and efficient transduction of the liver after peripheral vein infusion of self-complementary AAV vector results in stable therapeutic expression of human FIX in nonhuman primates. Blood 2007;109:1414-1421.

19. Nathwani AC, Rosales C, McIntosh J, et al. Long-term safety and efficacy following systemic administration of a self-complementary AAV vector encoding human FIX pseudotyped with serotype 5 and 8 capsid proteins. Mol Ther 2011;19:876-885.

20. Murrey DA, Naughton BJ, Duncan FJ, et al. Feasibility and safety of systemic rAAV9-hNAGLU delivery for treating mucopolysaccharidosis IIIB: toxicology, biodistribution, and immunological assessments in primates. Hum Gene Ther Clin Dev 2014;25:72-84.

21. Mingozzi F, Meulenberg JJ, Hui DJ, et al. AAV-1-mediated gene transfer to skeletal muscle in humans results in dosedependent activation of capsid-specific $\mathrm{T}$ cells. Blood 2009;114:2077-2086. 
22. Manno CS, Pierce GF, Arruda VR, et al. Successful transduction of liver in hemophilia by AAV-Factor IX and limitations imposed by the host immune response. Nat Med 2006;12:342-347.

23. Hildinger M, Auricchio A, Gao G, et al. Hybrid vectors based on adeno-associated virus serotypes 2 and 5 for muscle-directed gene transfer. J Virol 2001;75:6199-6203.

24. De BP, Heguy A, Hackett NR, et al. High levels of persistent expression of $\alpha 1$-antitrypsin mediated by the nonhuman primate serotype rh.10 adeno-associated virus despite preexisting immunity to common human adenoassociated viruses. Mol Ther 2006;13:67-76.

25. Fang H, Lai NC, Gao MH, et al. Comparison of adenoassociated virus serotypes and delivery methods for cardiac gene transfer. Hum Gene Ther Methods 2102;23:234-241.

26. Boutin S, Monteilhet V, Veron P, et al. Prevalence of serum IgG and neutralizing factors against adeno-associated virus (AAV) types $1,2,5,6,8$, and 9 in the healthy population: implications for gene therapy using AAV vectors. Hum Gene Ther 2010;21:704-712.

27. Gao MH, Lai NC, Miyanohara A, et al. Intravenous adenoassociated virus serotype 8 encoding urocortin- 2 provides sustained augmentation of left ventricular function in mice. Hum Gene Ther 2013;24:777-785.

28. Xiao X, Li J, Samulski RJ. Production of high-titer recombinant adeno-associated virus vectors in the absence of helper adenovirus. J Virol 1998;72:2224-2232.

29. Gao G, Ou G, Burnham MS, et al. Purification of recombinant adeno-associated virus vectors by column chromatography and its performance in vivo. Hum Gene Ther 2000;11:2079-2091.

30. Zolotukhin S, Potter M, Zolotukhin I, et al. Production and purification of serotype 1,2 , and 5 recombinant adenoassociated viral vectors. Methods 2002;28:158-167.

31. Bayat H, Swaney J, Ander A, et al. Progressive heart failure after myocardial infarction in mice. Basic Res Cardiol 2002;97:206-213.

32. Lai NC, Tang T, Gao MH, et al. Activation of cardiac adenylyl cyclase expression increases function of the failing ischemic heart in mice. J Am Coll Cardiol 2008;51:1490-1497.

33. Gao MH, Lai NC, Roth DM, et al. Adenylylcyclase increases responsiveness to catecholamine stimulation in transgenic mice. Circulation 1999;99:1618-1622.

34. Suarez J, Scott B, Dillmann WH. Conditional increase in SERCA2a protein is able to reverse contractile dysfunction and abnormal calcium flux in established diabetic cardiomyopathy. Am J Physiol 2008;295:R1439-R1445.

35. Gao MH, Tang T, Guo T, et al. Adenylyl cyclase type VI increases Akt activity and phospholamban phosphorylation in cardiac myocytes. J Biol Chem 2008;283:3352733535.

36. Gao MH, Tang T, Lai NC, et al. Beneficial effects of adenylyl cyclase type 6 (AC6) expression persist using a catalytically inactive AC6 mutant. Mol Pharmacol 2011;79: 381-388.
37. Bhargava V, Shabetai R, Mathiäsen RA, et al. Loss of adrenergic control of the force-frequency relation in heart failure secondary to idiopathic or ischemic cardiomyopathy. Am J Cardiol 1998;81:1130-1137.

38. Hare JM, Givertz MM, Creager MA, et al. Increased sensitivity to nitric oxide synthase inhibition in patients with heart failure: potentiation of beta-adrenergic inotropic responsiveness. Circulation 1998;97:161-166.

39. Swaminathan PD, Purohit A, Hund TJ, et al. Calmodulindependent protein kinase II: linking heart failure and arrhythmias. Circ Res 2012;110:1661-1677.

40. Zhang T, Maier LS, Dalton ND, et al. The delta C isoform of CaMKII is activated in cardiac hypertrophy and induces dilated cardiomyopathy and heart failure. Circ Res 2003;92:912-919.

41. He BJ, Joiner ML, Singh MV, et al. Oxidation of CaMKII determines the cardiotoxic effects of aldosterone. Nat Med 2011;17:1610-1618.

42. Sossalla S, Fluschnik N, Schotola H, et al. Inhibition of elevated $\mathrm{Ca}^{2+} /$ calmodulin-dependent protein kinase II improves contractility in human failing myocardium. Circ Res 2010;107:1150-1161.

43. Seguchi O, Takashima S, Yamazaki S, et al. A cardiac myosin light chain kinase regulates sarcomere assembly in the vertebrate heart. J Clin Invest 2007;117:2812-2824.

44. Chan JY, Takeda M, Briggs LE, et al. Identification of cardiac-specific myosin light chain kinase. Circ Res 2008;102:571-580.

45. Gu X, Liu X, Xu D, et al. Cardiac functional improvement in rats with myocardial infarction by up-regulating cardiac myosin light chain kinase with neuregulin. Cardiovasc Res 2010;88:334-343.

46. Ding P, Huang J, Battiprolu PK, et al. Cardiac myosin light chain kinase is necessary for myosin regulatory light chain phosphorylation and cardiac performance in vivo. $\mathrm{J}$ Biol Chem 2010;285:40819-40829.

47. Wang Z, Zhu T, Qiao C, et al. Adeno-associated virus serotype 8 efficiently delivers genes to muscle and heart. Nat Biotechnol 2015;23:321-328.

48. Bers DM. Cardiac excitation-contraction coupling. Nature 2002;415:198-205.

Address correspondence to: Dr. H. Kirk Hammond VA San Diego (111A) 3350 La Jolla Village Drive San Diego, CA 92161

E-mail: khammond@ucsd.edu

Received for publication December 29, 2014; accepted after revision March 6, 2015.

Published online: March 11, 2015. 